\title{
Hirshfeld Surfaces and Nonlinear Optics on Two Conformers of a Heterocyclic Chalcone
}

\author{
Jean M. F. Custodio, ${ }^{*, a, b}$ Cauã A. Moreira, ${ }^{b}$ Clodoaldo Valverde,, ,c,d \\ Gilberto L. B. de Aquino, ${ }^{b}$ Basílio Baseia ${ }^{a, e}$ and Hamilton B. Napolitano ${ }^{*, b, f}$ \\ ${ }^{a}$ Universidade Federal de Goiás, 74690-900 Goiânia-GO, Brazil \\ ${ }^{b}$ Universidade Estadual de Goiás, 75001-970 Anápolis-GO, Brazil \\ ${ }^{c}$ Escola Superior Associada de Goiânia, 74840-090 Goiânia-GO, Brazil \\ ${ }^{d}$ Universidade Paulista, 74845-090 Goiânia-GO, Brazil \\ ${ }^{e}$ Universidade Federal da Paraíba, 58051-970 João Pessoa-PB, Brazil \\ ${ }^{f}$ Centro Universitário de Anápolis, 75083-515, Anápolis-GO, Brazil
}

\begin{abstract}
Heterocyclic chalcones have been prominent in the scientific community due to various biological activities reported for these compounds. The structural knowledge of heterocyclic chalcones can help in the understanding of their mechanism of action. The Hirshfeld surfaces were used to study the supramolecular arrangement of two conformers present into asymmetric unit of the heterocyclic chalcone (2E)-3-(4-methylphenyl)-1-(pyridin-3-yl)-prop-2-en-1-one on crystalline state. In addition, the linear polarizability $(\alpha)$, the first hyperpolarizability $(\beta \| \mathrm{z})$, and the second hyperpolarizability $(\gamma)$ of the conformers were calculated to get a better insight on the linear and nonlinear optical behaviors of these structures in presence of solvent medium, as well as their band-gap energies. The Hirshfeld surfaces confirmed the presence of $\mathrm{C}-\mathrm{H} \cdots \mathrm{N}, \mathrm{C}-\mathrm{H} \cdots \mathrm{O}$ and $\mathrm{C}-\mathrm{H} \cdots \mathrm{C}$ interactions in packaging stabilization. Finally, the $2 \mathrm{D}$ fingeprint plot was used to the quantification of contacts and indicated that there are both $\pi \cdots \pi$ and $\mathrm{C}-\mathrm{H} \cdots \pi$ interactions present in the compound.
\end{abstract}

Keywords: heterocyclic chalcone, supramolecular arrangement, NLO properties

\section{Introduction}

Chalcones are chemical compounds formed by two aromatic rings linked by an aliphatic carbon chain with a carbonyl group and olefin portion. These molecules can be obtained naturally from plants or by synthetic methods, throughout Claisen-Schmidt reaction. They belong to flavonoid family, being considered as precursors of flavonoids, isoflavonoids, flavones and pyrazolines..$^{1-4}$ Also, chalcones and their derivatives have been studied mainly for their biological activities as anti-tumor, anti-inflammatory, anti-cancer, antioxidant, antibiotic, anti-malarial, antiprotozoal, anti-HIV and treatment of diabetes. Due to these activities, this class of compounds has a wide application in pharmaceutical industry. ${ }^{5-10}$

*e-mail: jeammarcos@hotmail.com; hbnapolitano@gmail.com
Additionally to chalcones, several studies have been reported about the heterocyclic chalcones due to their pharmacological activities, which are attributed to the structural aspects of these molecules, especially $(i)$ the unsaturated bond between the aliphatic carbons; (ii) the ketone group; and (iii) the presence of heteroatoms. ${ }^{6,11,12}$ The heterocyclic chalcones have a heteroaryl which contain an oxygen, sulfur or nitrogen. ${ }^{12,13}$ The pyridine is one type of aryl group with nitrogen as heteroatom, and is assigned to numerous biological activities, such as anti-microbial, anti-tumor and anti-viral. ${ }^{14}$ Several methods for synthesizing chalcones and derivates are described by the scientific community, and most typical reaction involves the Claisen-Schmidt condensation method. ${ }^{2,8,15}$ This method consists in a reaction between an aliphatic aldehyde or ketone with an aromatic aldehyde that may be given in the presence of a base or an acid. 
In the presence of a base, the asymmetric ketones react with the aromatic aldehyde through the less substituted position, and in presence of acid, through the more substituted. ${ }^{16}$

The study of crystalline state containing symmetrically independent molecules has a great importance, and it corresponds to a remarkable portion of the known cases. ${ }^{17}$ Zorkii and Razumaeva ${ }^{18}$ have made a statistical treatment with crystallographic data of 330 crystal structures with more than one molecule in the asymmetric unit, with $20 \%$ of these crystals containing independent conformers. Besides that, chemically identical molecules with significant differences on dihedral angles can coexist in a crystal. ${ }^{19}$ A recent study made by Taylor et al. ${ }^{20}$ discusses the motifs that lead crystals to contain two independent molecules in asymmetric unit and relationship between the number of independent molecules in asymmetric unit and the intermolecular interactions. The Hirshfeld surface analysis allows to locate and to quantify these interactions in the organic crystals. Intermolecular interactions could also provide an important effect to induced nonlinear optical (NLO) properties.

In addition, the research on organic crystals with good electric and optical properties has been extensively investigated in the literature. ${ }^{21-24}$ It was discovered that various applications with many properties of organic crystals transcend those of the inorganic ones. Studies of basic physics of nonlinear optical phenomena in solids remain extremely important for the field of nonlinear optics and for advances in technological communications. Nonlinear optical materials have attracted considerable attention due to their potential applications, including signal processing for integrated optical applications and other sections of material sciences, such as ultra-fast optical communications, e.g., the ultra-fast response time feature enabling applications of organic crystals in photonic devices. ${ }^{1,2,5}$

The heterocyclic chalcone (2E)-3-(4-methylphenyl)1-(pyridin-3-yl)-prop-2-en-1-one (MPH) was synthesized by heterogeneous base catalysis, and crystallized by slow evaporation from ethanol. ${ }^{25}$ The present work aims to compare structurally two independent molecules observed in the asymmetric unit and analyze the supramolecular arrangement, intermolecular interactions and contacts, and also Hirshfeld surfaces of both conformers. Furthermore, considering the conformers in solvent media we present a theoretical study using ab initio calculations to estimate dipole momentum, average of the linear polarizability $(\alpha)$, first hyperpolarizability $(\beta \| \mathrm{z})$ and the average second hyperpolarizability $(\gamma)$ of both conformers of the MPH compound.

\section{Experimental}

\section{Single crystal X-ray diffraction analysis}

The heterocyclic chalcone MPH was synthesized, crystallized and the X-ray experiment was undertaken at room temperature using the Bruker APEX II CCD diffractometer with graphite-monochromated MoK $\alpha$ radiation $(\lambda=0.71073 \AA$ ). From 4692 reflections collected [3684 reflections with $\mathrm{I}>2 \sigma(\mathrm{I})$ and 309 independent refined parameters], the crystallographic structure was resolved by SHELXS15 ${ }^{26,27}$ and refined by SHELXL15 ${ }^{26,27}$ softwares. All the hydrogen atoms were placed in calculated positions and refined with fixed individual displacement parameters $\left[\mathrm{U}_{\text {iso }}(\mathrm{H})=1.2\right.$ or $\left.1.5 \mathrm{U}_{\text {eq }}\right]$ according to the riding model (C-H bond lengths of 0.97 and $0.96 \AA$ for aromatic and methyl groups, respectively), except for the hydrogens involved in intermolecular interactions. The molecular representations, tables and pictures were generated by Mercury 3.7, ${ }^{28}$ VEGA ZZ 3.1.0 ${ }^{29}$ and Crystal Explorer v3. ${ }^{30}$ softwares. The data for the final structural refinement are shown in Table $1 .{ }^{25}$ The interactions and contacts were checked by the PARST7 software and analyzed by Hirshfeld surface, ${ }^{31}$ which is additionally a great tool for visualization of intermolecular interactions and contacts, since it brings their cross mapping of the relative distances to such contacts (see Supplementary Information for copies of data).

Table 1. Crystal data and structure refinement for $\mathrm{MPH}^{25}$

\begin{tabular}{lc}
\hline Empirical formula & $\mathrm{C}_{15} \mathrm{H}_{13} \mathrm{NO}$ \\
Formula weight / $\left(\mathrm{g} \mathrm{mol}^{-1}\right)$ & 223.26 \\
Temperature / K & 120 \\
Wavelength / $\mathrm{A}$ & 0.7103 \\
Crystal system, space group, $\mathrm{Z}$ & triclinic, $P \overline{1}, 4$ \\
Unit cell dimension & $a=5.9026(7) \AA, \alpha=69.654(2)^{\circ}$ \\
& $b=14.2199(16) \AA, \beta=84.231(2)^{\circ}$ \\
& $c=14.6772(17) \AA, \gamma=81.280(2)^{\circ}$ \\
Volume / A ${ }^{3}$ & $1140.2(2)$ \\
Absorption coefficient / mm ${ }^{-1}$ & 0.08 \\
F(000) & 472 \\
Reflections collected / unique & $23125 / 4692[\mathrm{R}(\mathrm{int})=0.0270]$ \\
Refinement method & full-matrix least-squares on $\mathrm{F}^{2}$ \\
Goodness-of-fit on F & 1.03 \\
Final R indices [I $>2 \sigma(\mathrm{I})]$ & $\mathrm{R}_{1}=0.041, \mathrm{wR} \mathrm{R}_{2}=0.105$ \\
\hline
\end{tabular}

Hirshfeld surface analysis

In the Hirshfeld surfaces theory, each atom is defined by a weight function $\left(\mathrm{w}_{\mathrm{a}}(\mathrm{r})\right)$, 
$\mathrm{w}_{\mathrm{a}}(\mathrm{r})=\rho_{\mathrm{a}}^{\mathrm{at}}(\mathrm{r}) / \sum_{\mathrm{i} \in \text { molecule }} \rho_{\mathrm{i}}^{\mathrm{at}}(\mathrm{r})$

where the individuals $\rho_{a}^{\text {at }}(\mathrm{r})$ are spherically-averaged electron densities of the various atoms. ${ }^{32}$ In this sense, the definition of the electron density of an atomic fragment is

$\rho_{\mathrm{a}}(\mathrm{r})=\mathrm{w}_{\mathrm{a}}(\mathrm{r}) \rho^{\mathrm{mol}}(\mathrm{r})$

where $\rho^{\mathrm{mol}}(\mathrm{r})$ is the molecular electron density. ${ }^{32}$ These surfaces take into account the distance from the surface to the nearest atom interior to the surface ( $d i$, where the molecule acts as intermolecular contacts donors more strong) and the distance from the surface to the nearest atom exterior to the surface ( $d e$, where the molecule acts as intermolecular contacts receptor more strong), obtained through the equation 3 :

$d_{\text {norm }}=\frac{d_{i}-r_{i}^{\text {vdW }}}{r_{i}^{\text {vdW }}}+\frac{d_{e}-r_{e}^{\text {vdW }}}{r_{e}^{\text {vdW }}}$

with $\mathrm{r}_{\mathrm{i}}^{\mathrm{vdW}}$ and $\mathrm{r}_{\mathrm{e}}^{\mathrm{vdW}}$ corresponding to interior and exterior van der Waals radii, respectively; and $\mathrm{d}_{\text {norm }}$ to normalized contact distances. The $\mathrm{C}-\mathrm{H} \cdots \pi$ and $\pi \cdots \pi$ interactions are recognized by Hirshfeld surface of shape index type, $S$, identifying empty complementary regions (red) and completed (blue) (Figure 1), where two molecules meet. ${ }^{33}$ These curvature function is defined in terms of principal curvatures $\kappa_{1}$ and $\kappa_{2}$,

$\mathrm{S}=\frac{2}{\pi} \arctan \left(\frac{\kappa_{1}+\kappa_{2}}{\kappa_{1}-\kappa_{2}}\right)$

A final analysis of the intermolecular contacts can be conducted by two-dimensional projection of the Hirshfeld surface of $d e$ against $d i$, namely fingerprints. ${ }^{34}$

\section{Computational details}

To calculate the total dipole moment $(\mu)$ of the MPH molecule, the average polarization $(\langle\alpha\rangle)$, first hyperpolarizability $\left(\beta_{\|}\right)$and average second hyperpolarizability $(\langle\gamma\rangle)$, the following equations 5-8 were used:

$\mu=\left(\mu_{\mathrm{x}}^{2}+\mu_{\mathrm{y}}^{2}+\mu_{\mathrm{z}}^{2}\right)^{\frac{1}{2}}$

$\langle\alpha\rangle=\frac{\alpha_{x x}+\alpha_{y y}+\alpha_{z z}}{3}$

$\beta_{\|}=\frac{1}{5} \sum_{\mathrm{i}=1}^{3}\left(\beta_{\mathrm{zii}}+\beta_{\mathrm{izi}}+\beta_{\mathrm{iiz}}\right)$ where $\mathrm{z}$ is oriented in the direction of the dipole moment of the molecule and

$\langle\gamma\rangle=\frac{1}{15} \sum_{\mathrm{i}, \mathrm{j}=\mathrm{x}, \mathrm{y}, \mathrm{z}}\left(\gamma_{\mathrm{iijj}}+\gamma_{\mathrm{ijij}}+\gamma_{\mathrm{ijji}}\right)$

Among the several applications of the NLO properties, we can cite the second harmonic generation, third harmonic and electrooptical effects; the NLO properties are governed by molecular hyperpolarizabilities. In what follows, all results were obtained using Gaussian0935 software, with functional CAM-B3LYP and basis set $6-311 / \mathrm{G}^{++}(\mathrm{d}, \mathrm{p})$.

\section{Results and Discussion}

Hirshfeld surface analysis

The MPH is a chalcone analog in which there is a nitrogen heteroatom in the aromatic ring nearest the carbonyl group. The toluyl and pyridine groups are linked by olefin portion and carbonyl group, respectively. MPH compound crystallizes in triclinic centrosymmetric space group $P \overline{1}$, with cell parameters $a=5.9026$ (7) $⿱ ㇒, b=14.2199$ (16) , $c=14.6772$ (17) $\AA, \alpha=69.654(2)^{\circ}, \beta=84.231$ (2) ${ }^{\circ}$ and $\gamma=81.280(2)^{\circ}$. The unit cell is composed of two asymmetrical units formed by two independent molecules. The conformers inside the asymmetric units are shown in Figure 1, named MPH- $\alpha$ and MPH- $\beta$. The conformers MPH- $\alpha$ and MPH- $\beta$ have the same chemical composition, but their structures differ mainly in planarity. This difference can be evaluated throughout most disagreeable parameters: dihedral angles and angles of the planes formed by the aromatic rings. The conformer MPH- $\alpha$ shows lower flatness, with a dihedral angle $\mathrm{C} 3-\mathrm{C} 4-\mathrm{C} 6-\mathrm{C} 7$ equal to $55.94^{\circ}$, in contrast with a dihedral angle of only $7.9^{\circ}$ in corresponding carbons of MPH- $\beta$ (C18-C19-C21-C22). The toluene and pyridine rings form angles of $41.41^{\circ}$ and $17.93^{\circ}$ to MPH- $\alpha$ and MPH- $\beta$, respectively. Figure 2 shows the overlap of both conformers MPH (the pyridine groups of MPH- $\alpha$ and MPH- $\beta$ form an angle of $55.22^{\circ}$ ).

Table 2 shows all MPH interactions and because there are two conformers of the analyzed compound, interactions were divided into MPH- $\alpha$ and MPH- $\beta$. C6 $\cdots$. 66 and $\mathrm{C} 16-\mathrm{H} 16 \cdots \mathrm{N} 1$ interactions are related to conformer MPH- $\alpha$, while $\mathrm{C} 1-\mathrm{H} 1 \cdots \mathrm{N} 2, \mathrm{C} 29-\mathrm{H} 29 \cdots \mathrm{O} 2, \mathrm{C} 25-\mathrm{H} 25 \cdots \mathrm{O} 2$ and $\mathrm{C} 20-\mathrm{H} 20 \cdots \mathrm{C} 18$ interactions belong to conformer MPH- $\beta$. Furthermore, two conformers of the same asymmetric unit are bonded by $\mathrm{C} 11-\mathrm{H} 11 \cdots \mathrm{C} 27$ interaction. All hydrogen bonds described were calculated and validated by PLATON software. ${ }^{37}$ Also, their parameters are in good agreement with data on literature. ${ }^{4,38}$ 


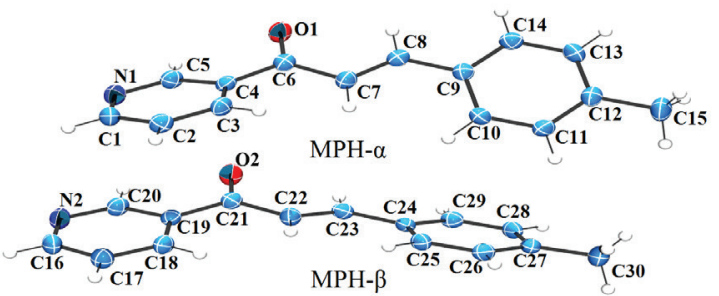

(a)

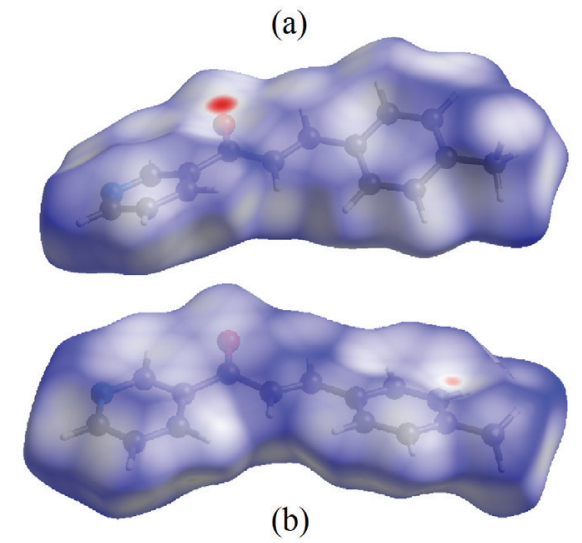

(b)

Figure 1. The ORTEP $^{36}$ diagram of ellipsoids at $30 \%$ probability level with the atomic numbering scheme (a) and Hirshfeld Surfaces for MPH showing the molecular units MPH- $\alpha$ and MPH- $\beta$ of asymmetric unit (b). All bonds are in the normal range and hydrogen atoms are shown as spheres of arbitrary radii.

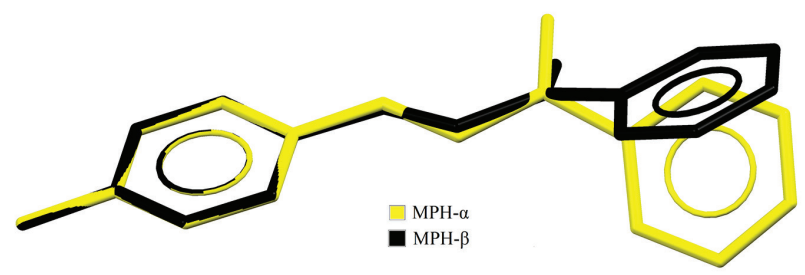

Figure 2. Overlap of MPH conformers.

The weak interactions of type $\mathrm{C}-\mathrm{H} \cdots \mathrm{C}$ has been described in the literature as qualified hydrogen bond because of the contribution on molecular arrangement stability they provide. ${ }^{39,40}$ In addition to interactions $\mathrm{C} 1-\mathrm{H} 1 \cdots \mathrm{N} 2\left[\mathrm{D} \cdots \mathrm{A}=3.503 \AA\right.$ 列 $-\mathrm{H} \cdots \mathrm{A}=140.51^{\circ}$; symmetry code: $-\mathrm{x},-\mathrm{y}, 2-\mathrm{z}]$ and $\mathrm{C} 16-\mathrm{H} 16 \cdots \mathrm{N} 1$ $\left[\mathrm{D} \cdots \mathrm{A}=3.471 \AA\right.$ $\mathrm{A}, \mathrm{D}-\mathrm{H} \cdots \mathrm{A}=144.08^{\circ}$; symmetry code: $-\mathrm{x}$, $-\mathrm{y}, 2-\mathrm{z}]$, the interaction $\mathrm{C} 11-\mathrm{H} 11 \cdots \mathrm{C} 27[\mathrm{D} \cdots \mathrm{A}=3.472 \AA$, $\mathrm{D}-\mathrm{H} \cdots \mathrm{A}=128.82^{\circ}$; symmetry code: $\left.\mathrm{x}, \mathrm{y},-1+\mathrm{z}\right]$ plays an important role in the MPH crystal packing because it forms tetramers, as shown in Figure 3. Besides the tetramer depicted, Figure 3 also shows the dimer on packing stabilized by $\mathrm{C} 29-\mathrm{H} 29 \cdots \mathrm{O} 2$ interaction $[\mathrm{D} \cdots \mathrm{A}=3.260 \AA$, $\mathrm{D}-\mathrm{H} \cdots \mathrm{A}=135.72^{\circ}$; symmetry code: $\left.-\mathrm{x}, 1-\mathrm{y}, 1-\mathrm{z}\right]$.

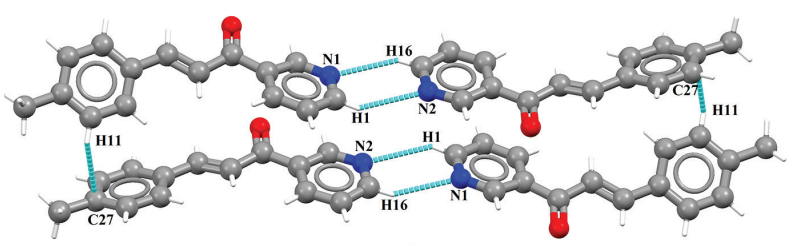

(a)

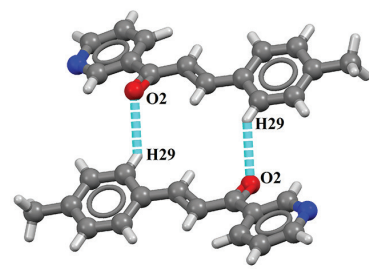

(b)

Figure 3. Synthons formed in MPH showing the tetramer stabilized by

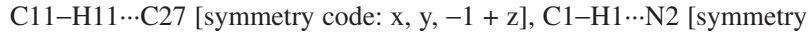
code: $-\mathrm{x},-\mathrm{y}, 2-\mathrm{z}$ ] and $\mathrm{C} 16-\mathrm{H} 16 \cdots \mathrm{N} 1$ [symmetry code: $-\mathrm{x},-\mathrm{y}, 2-\mathrm{z}$ ] interactions (a) and the dimer stabilized by $\mathrm{C} 29-\mathrm{H} 29 \cdots \mathrm{O} 2$ [symmetry code: $-\mathrm{x}, 1-\mathrm{y}, 1-\mathrm{z}](\mathrm{b})$.

Considering the tetramer as supramolecular arrangement unit, C6 ‥C6 interaction [C...C $=3.231 \AA$; symmetry code: $-\mathrm{x},-\mathrm{y}, 1-\mathrm{z}]$ contributes to the formation of a layer, stacking the tetramers in a ladder-like motifs almost along the $\mathrm{c}$ axis. Added to such interaction, $\mathrm{C} 29-\mathrm{H} 29 \cdots \mathrm{O} 2$ $\left[\mathrm{D} \cdots \mathrm{A}=3.260 \AA, \mathrm{D}-\mathrm{H} \cdots \mathrm{A}=135.72^{\circ}\right.$; symmetry code: $-\mathrm{x}, 1-\mathrm{y}, 1-\mathrm{z}], \mathrm{C} 25-\mathrm{H} 25 \cdots \mathrm{O} 2[\mathrm{D} \cdots \mathrm{A}=3.485 \AA$, $\mathrm{D}-\mathrm{H} \cdots \mathrm{A}=138.96^{\circ}$; symmetry code: $\left.1+\mathrm{x}, \mathrm{y}, \mathrm{z}\right]$ and

Table 2. Inter/intramolecular interactions of MPH

\begin{tabular}{|c|c|c|c|c|c|}
\hline $\mathrm{D}-\mathrm{H} \cdots \mathrm{A}$ & $\mathrm{d}(\mathrm{D}-\mathrm{H})$ & $\mathrm{d}(\mathrm{H} \cdots \mathrm{A})$ & $\mathrm{d}(\mathrm{D} \cdots \mathrm{A})$ & $\mathrm{d}(\mathrm{DH} \cdots \mathrm{A}) /^{\circ}$ & Symmetry code \\
\hline \multicolumn{6}{|c|}{ Conformer MPH- $\alpha$} \\
\hline $\mathrm{C} 1-\mathrm{H} 1 \cdots \mathrm{N} 2$ & 0.950 & 2.717 & 3.503 & 140.51 & $-\mathrm{x},-\mathrm{y}, 2-\mathrm{z}$ \\
\hline $\mathrm{C} 6 \cdots \mathrm{C} 6$ & \multicolumn{4}{|c|}{$\mathrm{d}(\mathrm{C} 6 \cdots \mathrm{C} 6)=3.231$} & $-\mathrm{x},-\mathrm{y}, 1-\mathrm{z}$ \\
\hline \multicolumn{6}{|c|}{ Conformer MPH- $\beta$} \\
\hline $\mathrm{C} 11-\mathrm{H} 11 \cdots \mathrm{C} 27$ & 0.950 & 2.797 & 3.472 & 128.82 & intramolecular \\
\hline $\mathrm{C} 16-\mathrm{H} 16 \cdots \mathrm{N} 1$ & 0.949 & 2.657 & 3.471 & 144.08 & $-\mathrm{x},-\mathrm{y}, 2-\mathrm{z}$ \\
\hline $\mathrm{C} 29-\mathrm{H} 29 \cdots \mathrm{O} 2$ & 0.949 & 2.513 & 3.260 & 135.72 & $-\mathrm{x}, 1-\mathrm{y}, 1-\mathrm{z}$ \\
\hline $\mathrm{C} 25-\mathrm{H} 25 \cdots \mathrm{O} 2$ & 0.950 & 2.712 & 3.485 & 138.96 & $1+x, y, z$ \\
\hline C20-H $20 \cdots \mathrm{C} 18$ & 0.950 & 2.873 & 3.702 & 146.47 & $-1+\mathrm{x}, \mathrm{y}, \mathrm{z}$ \\
\hline
\end{tabular}




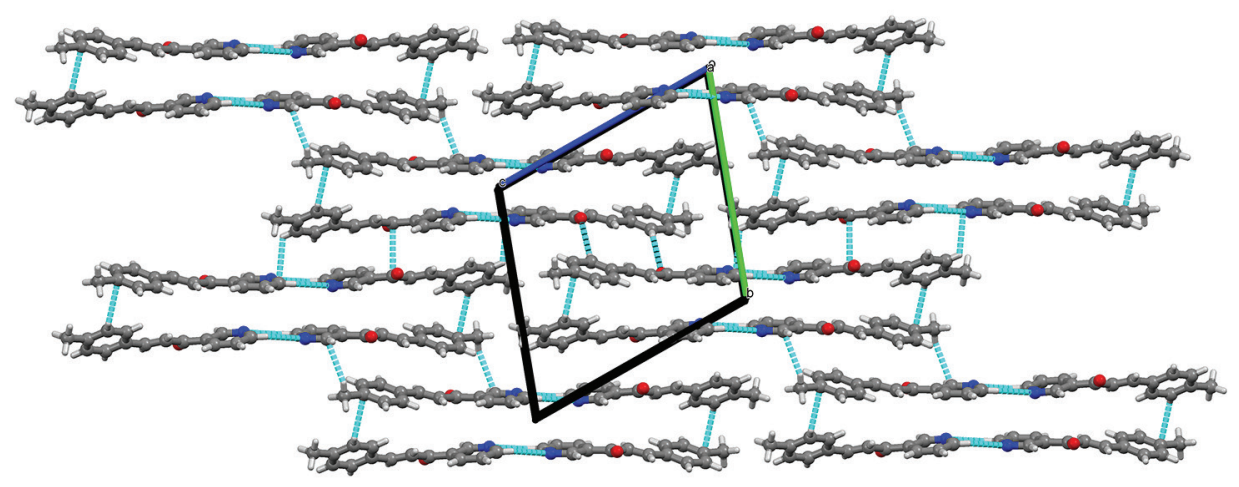

Figure 4. Supramolecular arrangement of MPH with ladder-like motifs.

$\mathrm{C} 20-\mathrm{H} 20 \cdots \mathrm{C} 18\left[\mathrm{D} \cdots \mathrm{A}=3.702 \AA, \mathrm{D}-\mathrm{H} \cdots \mathrm{A}=146.47^{\circ}\right.$; symmetry code: $-1+\mathrm{x}, \mathrm{y}, \mathrm{z}]$ interactions contribute to the supramolecular arrangement shown in Figure 4.

In addition to geometric analysis obtained by Mercury software, intra and intermolecular interactions are quantitatively analyzed by Hirshfeld surface analysis. This analysis consists in mapping interactions considering $d i$ (distance between centers of internal atoms to the surface) and de (distance between the nucleus of the atoms of an external molecule to the Hirshfeld surface). In Figure 5, the normalized $d_{\text {norm }}$ surfaces for MPH- $\alpha$ (a) and MPH- $\beta$ (b) are shown, (i.e., the normalized contact distance) ${ }^{8}$ Even with the same chemical composition, $\mathrm{C} 16-\mathrm{H} 16 \cdots \mathrm{N} 1$ interaction (3) is stronger than $\mathrm{C} 1-\mathrm{H} 1 \cdots \mathrm{N} 2$ interaction (1), indicating that MPH- $\alpha$ is more effective as acceptor electron density while MPH- $\beta$ is a better donor. The $\mathrm{C} 11-\mathrm{H} 11 \cdots \mathrm{C} 27$ intramolecular interaction is represented by contact (2) on the Hirshfeld surface with medium strength, confirmed by the distance of $2.797 \AA$ (D)A . The tetramer of Figure 3 provides the approach of two MPH- $\alpha$ conformers, making possible the interaction between electron rich region of $\mathrm{C}$ atom in one conformer with electron deficient region of $\mathrm{C}$ atom in another conformer ${ }^{10}$ resulting in a strong C6 $\cdots \mathrm{C} 6$ interaction (4). The conformer MPH- $\beta$ shows $\mathrm{C}-\mathrm{H} \cdots \mathrm{C}(6)$ and bifurcated $\mathrm{C}-\mathrm{H} \cdots \mathrm{O}$ interactions (5) and (7). The presence of the nitrogen atom on the heterocycle increases the positive charge of hydrogen atom at para position, making pyridine more effective as a " $\pi$-hydrogen bond" donor ${ }^{11}$ and resulting in $\mathrm{C} 20-\mathrm{H} 20 \cdots \mathrm{C} 18$ interaction (6). Finally, Figure 5 shows the high intensity of (5) and (7) contacts, indicating the receiver nature of the oxygen atom of $\mathrm{C} 29-\mathrm{H} 29 \ldots \mathrm{O} 2$ and $\mathrm{C} 25-\mathrm{H} 25 \cdots \mathrm{O} 2$ interactions.

The crystal packing is also stabilized by $\mathrm{C}-\mathrm{H} \cdots \pi$ and $\pi \cdots \pi$ interactions, as can be seen in Figure 6. For better understanding, centroids were created in MPH, namely: pyridine ring of MPH- $\alpha(\mathrm{Cg} 1)$; toluyl group of MPH- $\alpha(\mathrm{Cg} 2)$; pyridine ring of MPH- $\beta$ (Cg3); toluyl

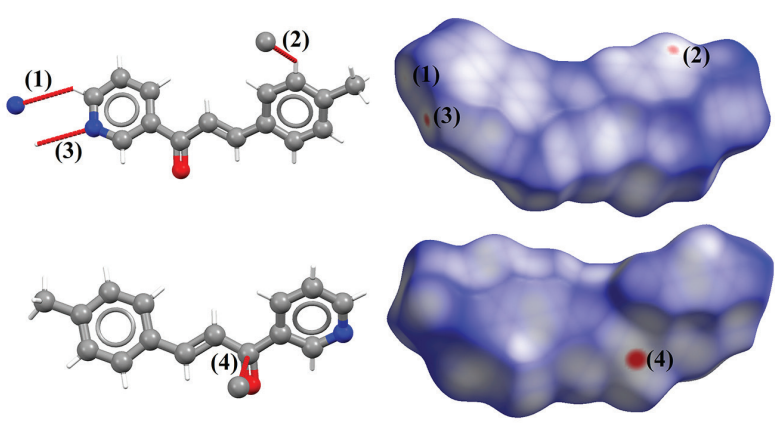

(a)

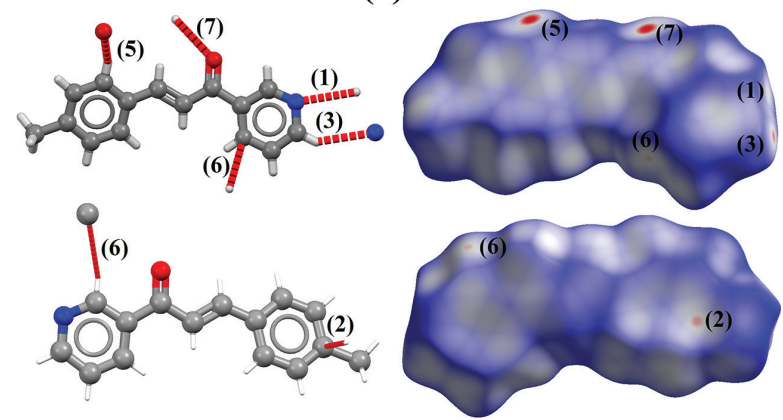

(b)

Figure 5. Representation of intra/intermolecular interactions and Hirshfeld surfaces for MPH- $\alpha$ (a) and MPH- $\beta$ (b). Red colors indicate greater strength in the interaction.

group of MPH- $\beta$ (Cg4). C30-H30C ... Cg3 interaction (8) $\left[\mathrm{D} \cdots \mathrm{Cg}=4.059 \AA, \mathrm{D}-\mathrm{H} \cdot \mathrm{Cg}=120.24^{\circ}\right.$; symmetry code: $1-\mathrm{x}, 1-\mathrm{y}, 1-\mathrm{z}$ ] forms a dimer of two MPH- $\alpha$ units and contribute to the stability of the layer of tetramers (Figure 4), packing them in a ladder-like motifs almost along the $\mathrm{b}$ axis. The blue region (8) in Figures $6 \mathrm{c}$ and $6 \mathrm{~d}$ indicates the $\mathrm{C}-\mathrm{H}$ donor of $\mathrm{C} 30-\mathrm{H} 30 \mathrm{C}$ while the red region (8) in Figure 6d indicates the $\mathrm{Cg} 3 . \mathrm{C} 11-\mathrm{H} 11 \cdots \mathrm{Cg} 4$ intramolecular interaction (9) $[\mathrm{D} \cdots \mathrm{Cg}=3.658 \AA$, $\left.\mathrm{D}-\mathrm{H} \cdots \mathrm{Cg}=109.36^{\circ}\right]$ is represented by a large red regions of concave curvature (9) in Figure $6 \mathrm{c}(\mathrm{Cg} 4)$ and blue regions (9) in Figures $6 \mathrm{~b}$ and $6 \mathrm{c}(\mathrm{C} 11-\mathrm{H} 11)$, contributing to the stability of the tetramer. Besides the aforementioned interactions, tetramer is also stabilized by the $\mathrm{Cg} 1 \cdots \mathrm{Cg} 3$ 
hydrophobic interaction $[\mathrm{Cg} \cdots \mathrm{Cg}=4.004 \AA$; symmetry code: $x, y, z]$. See two triangular shapes denoted by (10), in Figures $6 \mathrm{~b}$ and $6 \mathrm{c}$. The first triangle, red, combined with the second triangle, blue, form a kind of "bowtie" indicating the presence of $\pi-\pi$ interactions there. The last $\mathrm{C}-\mathrm{H} \cdots \pi$ interaction is represented by depression above of $\mathrm{Cg} 3$ (11) in Figure 6d corresponding to $\mathrm{C} 23-\mathrm{H} 23 \cdots \mathrm{Cg} 4$ interaction $\left[\mathrm{D} \cdots \mathrm{Cg}=3.565 \AA\right.$, D-H $\cdots \mathrm{Cg}=73.49^{\circ}$; symmetry code: $-1+\mathrm{x}, \mathrm{y}, \mathrm{z}]$.

Fingerprints are a great analysis tools in order to characterize each contact individually, according to its nature and percentage in the crystal packing. The twodimensional projections of the Hirshfeld surface, named fingerprint, are graphics of $d e$ against $d i^{9}$ and are shown in Figure 7 (MPH- $\alpha$ on the left and MPH- $\beta$ on the right). Both conformers MPH- $\alpha$ and MPH- $\beta$ show a low percentage of $\mathrm{C} \cdots \mathrm{C}$ contacts, but they play an important role in the structure: in $\mathrm{MPH}-\alpha$ relates to $\mathrm{C} 6 \cdots \mathrm{C} 6$ and $\mathrm{Cg} 1 \cdots \mathrm{Cg} 3$ interactions, whereas in MPH- $\beta$ relates only to $\mathrm{Cg} 1 \cdots \mathrm{Cg} 3$ interaction. The highlighted regions (10) in Figure $7 \mathrm{~b}$ are due to pyridine rings overlapping. The $\mathrm{C} \cdots \mathrm{H}$ contacts are characterized by the shape of "wings" namely (11) in Figure $7 \mathrm{c}$ and are slightly different for conformers. In MPH- $\alpha$ indicate hydrophobic interactions involving $\mathrm{Cg} 1$ and $\mathrm{Cg} 3$ while in MPH- $\beta$ indicates the hydrophobic interaction involving $\mathrm{Cg} 4$ and non-classical interaction $\mathrm{C}-\mathrm{H} \cdots \mathrm{C}$ caused by delocalized electron of pyridine $(\mathrm{C} 20-\mathrm{H} 20 \cdots \mathrm{C} 18)$. This fact explains the percentage difference in both conformers (29.4\% in MPH- $\alpha$ against $27.7 \%$ in MPH- $\beta$ ). Note the difference between the $\mathrm{H} \cdots \mathrm{O}$ plots in Figure 7d: the higher values of $d i$ and $d e$ indicate that the weaker hydrogen bonds dominate the packaging MPH- $\alpha$, manifesting as spots dispersed in the upper region (12). This pattern is not noted for MPH- $\beta$, replaced by a pair of sharp spikes (13), indicating the prevalence of $\mathrm{C}-\mathrm{H} \cdots \mathrm{O}$ stronger interactions. The upper spike (where $d e>d i)$ corresponds to the hydrogen-bond donor and the lower spike (where $d e<d i$ ) corresponds to the hydrogenbond acceptor. ${ }^{9}$ There are not major differences in the $\mathrm{H} \cdots \mathrm{H}$ (Figure 7e) and $\mathrm{N} \cdots \mathrm{H}$ (Figure 7f) contacts for the conformers analyzed.

\section{Nonlinear optical properties}

In the literature, there are two ways to treat solvents: one of them explicitly employs classical or quantum dynamics, the other does this implicitly. In this work, the implicit form was used and among the existing models the polarizable continuum model (PCM) was chosen. In this case the calculations were implemented for the dynamic electrical properties MPH- $\alpha$ and MPH- $\beta$ at the frequency $\omega=0.0239$ and 0.0428 a.u. and for different solvents, such as gas-phase, acetone, chloroform, dimethyl sulfoxide (DMSO), ethanol, methanol and water. Tables 3-6 show the values of the NLO properties.

Comparing the linear polarizability $\alpha(-\omega ; \omega)$ for the cases gas-phase and chloroform extremes, for MPH- $\alpha$ at frequency $\omega=0.0239$ a.u. (0.0428 a.u.), it was obtained an increase of $13.77 \%(14.12 \%)$ whereas for the first hyperpolarizability $\beta \| \mathrm{z}(-2 \omega ; \omega, \omega)$ the increase was $77.61 \%$

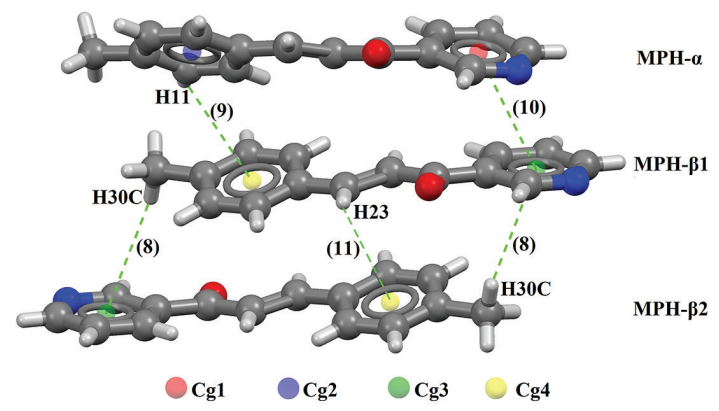

(a)

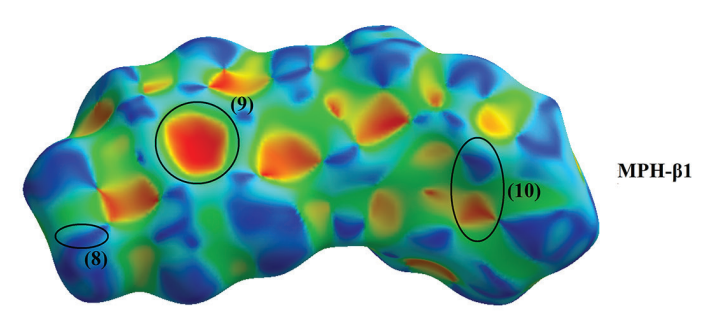

(c)

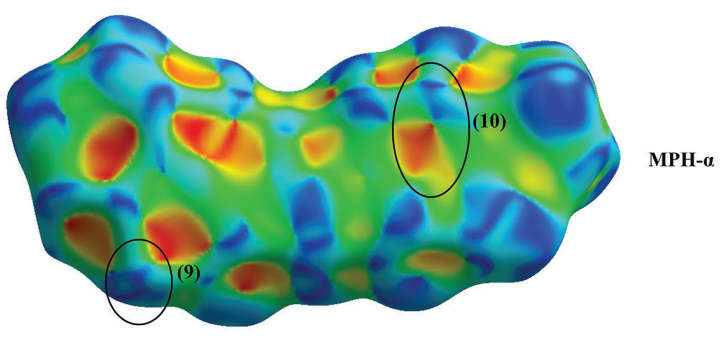

(b)

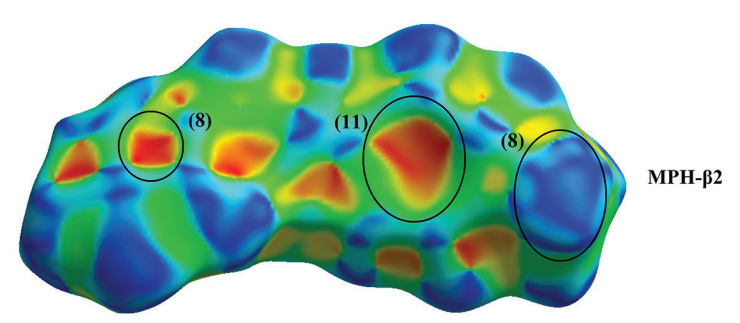

(d)

Figure 6. (a) Representation of $\mathrm{C}-\mathrm{H} \cdots \pi$ and $\pi \cdots \pi$ interactions by dotted lines, establishing the crystal packing of $\mathrm{MPH}$. $\mathrm{Cg} 1$ : pyridine ring of MPH- $\alpha$; $\mathrm{Cg} 2$ : toluyl group of MPH- $\alpha$; $\mathrm{Cg} 3$ : pyridine ring of MPH- $\beta$; Cg4: toluyl group of MPH- $\beta$. (b), (c) and (d): Hirshfeld surfaces shape index of MPH- $\alpha$ and MPH- $\beta$. 


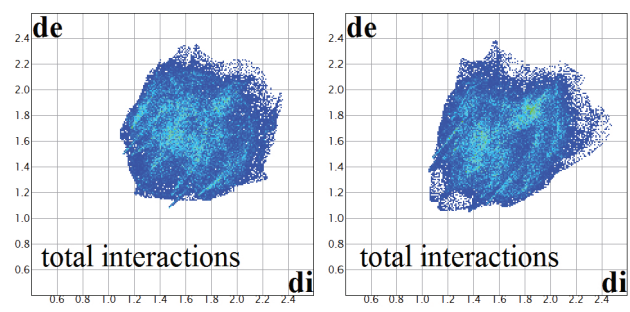

(a)
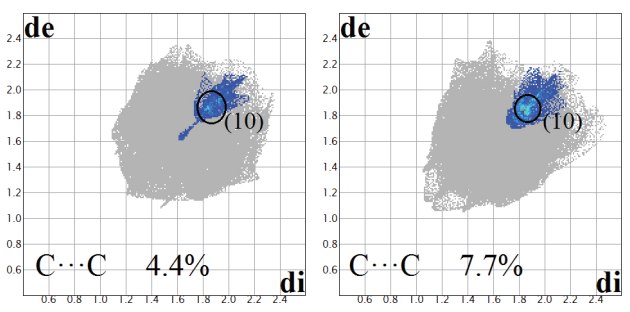

(b)

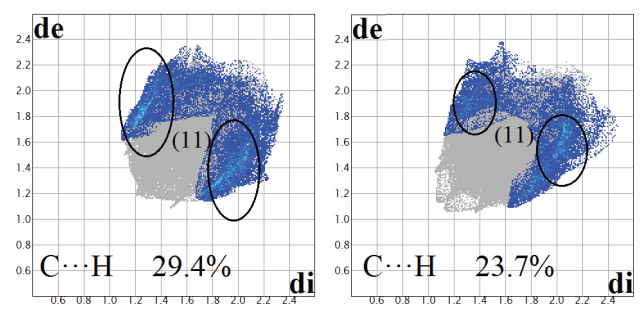

(c)

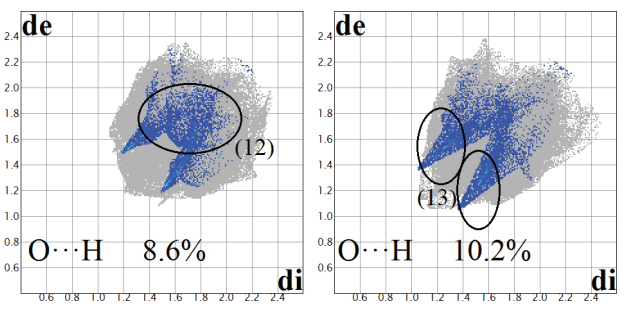

(d)

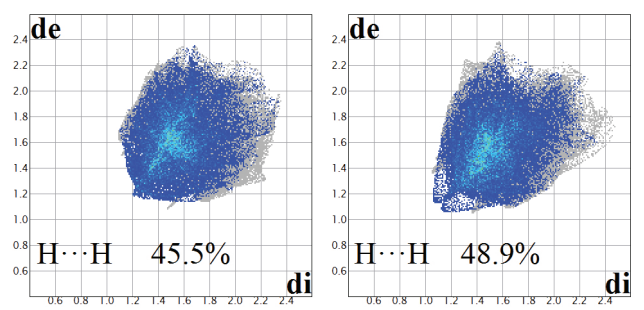

(e)
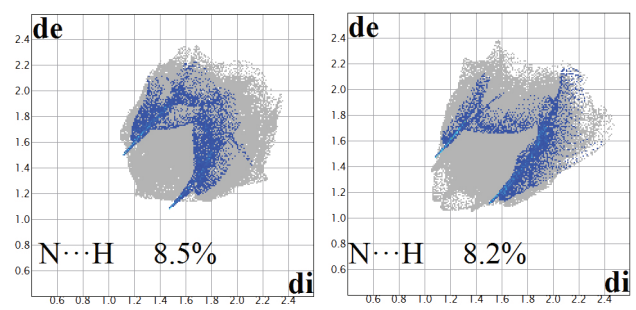

(f)

Figure 7. Fingerprint of the MPH (MPH- $\alpha$ on the left and MPH- $\beta$ on the right): (a) total interactions; (b) $\mathrm{O} \cdots \mathrm{H}$; (c) $\mathrm{C} \cdots \mathrm{C}$; (d) $\mathrm{H} \cdots \mathrm{H}$; (e) $\mathrm{C} \cdots \mathrm{H}$; (f) $\mathrm{N} \cdots \mathrm{H}$. The outline of the full fingerprint is shown in gray. di: the closest internal distance from a given point on the Hirshfeld surface; de: the closest external contacts.

Table 3. MPH- $\alpha$ - pbe1pbe/6-311+G(d) results for the dynamic linear polarizability (in $10^{-24}$ esu), first hyperpolarizability (in $10^{-30}$ esu) and second hyperpolarizability (in $10^{-36} \mathrm{esu}$ ) of various solvents $\mathrm{MPH}-\alpha$ for the frequency $\omega=0.0239$ a.u. $(1906.4 \mathrm{~nm})$

\begin{tabular}{lccccc}
\hline Medium & $\alpha(-\omega ; \omega)$ & $\beta \| \mathrm{z}(-\omega ; \omega, 0)$ & $\beta \| \mathrm{z}(-2 \omega ; \omega, \omega)$ & $\gamma(-\omega ; \omega, 0,0)$ & \multicolumn{2}{c}{$\gamma(-2 \omega ; \omega, \omega, 0)$} \\
\hline Gas-phase & 29.97 & -10.83 & -12.15 & 62.02 & 68.82 \\
Methanol & 33.46 & -22.26 & -21.90 & 135.21 & 130.26 \\
Water & 22.62 & -22.63 & -22.16 & 137.96 & 132.12 \\
Acetone & 33.66 & -22.21 & -22.11 & 134.51 & 131.37 \\
Ethanol & 33.68 & -22.38 & -22.23 & 135.79 & 132.25 \\
DMSO & 34.09 & -23.19 & -23.16 & 141.37 & 138.31 \\
Chloroform & 34.09 & -20.33 & -21.58 & 120.61 & 126.65 \\
\hline
\end{tabular}

Table 4. MPH- $\alpha$ - pbe1pbe/6-311+G(d) results for the dynamic linear polarizability (in $10^{-24}$ esu), first hyperpolarizability (in $10^{-30}$ esu) and second hyperpolarizability (in $10^{-36} \mathrm{esu}$ ) of various solvents $\mathrm{MPH}-\alpha$ for the frequency $\omega=0.0428$ a.u. $(1064.1 \mathrm{~nm}$ )

\begin{tabular}{lccccc}
\hline Medium & $\alpha(-\omega ; \omega)$ & $\beta \| z(-\omega ; \omega, 0)$ & $\beta \| z(-2 \omega ; \omega, \omega)$ & $\gamma(-\omega ; \omega, 0,0)$ & $\gamma(-2 \omega ; \omega, \omega, 0)$ \\
\hline Gas-phase & 30.52 & -12.3 & -18.78 & 69.60 & 104.0 \\
Methanol & 34.20 & -25.64 & -35.91 & 155.46 & 217.94 \\
Water & 23.12 & -26.08 & -36.39 & 158.71 & 221.63 \\
Acetone & 34.40 & -25.59 & -36.30 & 154.69 & 219.93 \\
Ethanol & 34.43 & -25.79 & -36.52 & 156.20 & 221.70 \\
DMSO & 34.85 & -26.76 & -38.24 & 162.89 & 233.52 \\
Chloroform & 34.83 & -23.42 & -35.33 & 138.42 & 209.94 \\
\hline
\end{tabular}


Table 5. MPH- $\beta$ - pbe1pbe/6-311+G(d) results for the dynamic linear polarizability (in $10^{-24}$ esu), first hyperpolarizability (in $10^{-30}$ esu) and second hyperpolarizability (in $10^{-36} \mathrm{esu}$ ) of various solvents MPH- $\beta$ for the frequency $\omega=0.0239$ a.u. $(1906.4 \mathrm{~nm}$ )

\begin{tabular}{lccccc}
\hline Medium & $\alpha(-\omega ; \omega)$ & $\beta \| \mathrm{z}(-\omega ; \omega, 0)$ & $\beta \| \mathrm{z}(-2 \omega ; \omega, \omega)$ & $\gamma(-\omega ; \omega, 0,0)$ & $\gamma(-2 \omega ; \omega, \omega, 0)$ \\
\hline Gas-phase & 29.97 & -10.62 & -11.91 & 62.02 & 68.82 \\
Methanol & 33.46 & -21.81 & -21.45 & 135.23 & 130.28 \\
Water & 33.52 & -22.17 & -21.70 & 138.00 & 132.13 \\
Acetone & 33.66 & -21.75 & -21.66 & 134.55 & 131.40 \\
Ethanol & 33.68 & -21.92 & -21.77 & 135.80 & 132.26 \\
DMSO & 34.09 & -22.71 & -22.67 & 141.44 & 138.36 \\
Chloroform & 34.09 & -19.91 & -21.13 & 120.60 & 126.64 \\
\hline
\end{tabular}

Table 6. MPH- $\beta$ - pbe1pbe/6-311+G(d) results for the dynamic linear polarizability (in $10^{-24}$ esu), first hyperpolarizability (in $10^{-30}$ esu) and second hyperpolarizability (in $10^{-36}$ esu) of various solvents MPH- $\beta$ for the frequency $\omega=0.0428$ a.u. $(1064.1 \mathrm{~nm}$ )

\begin{tabular}{lccccc}
\hline Medium & $\alpha(-\omega ; \omega)$ & $\beta \| \mathrm{z}(-\omega ; \omega, 0)$ & $\beta \| \mathrm{z}(-2 \omega ; \omega, \omega)$ & $\gamma(-\omega ; \omega, 0,0)$ & $\gamma(-2 \omega ; \omega, \omega, 0)$ \\
\hline Gas-phase & 30.52 & -12.06 & -18.41 & 69.6 & 128.76 \\
Methanol & 34.20 & -25.12 & -35.16 & 155.49 & 218.00 \\
Water & 34.26 & -25.54 & -35.62 & 158.72 & 221.66 \\
Acetone & 34.40 & -25.06 & -35.54 & 154.73 & 220.0 \\
Ethanol & 34.43 & -25.26 & -35.76 & 156.21 & 221.72 \\
DMSO & 34.85 & -26.20 & -37.42 & 162.96 & 233.59 \\
Chloroform & 34.83 & -22.93 & -34.59 & 138.42 & 209.93 \\
\hline
\end{tabular}

$(88.13 \%)$; the values of the second hyperpolarizability $\gamma(-2 \omega, \omega, \omega, 0)$ showed an increase of $88.03 \%(101.87 \%)$. When compared the gas-phase with the DMSO solvent for the conformer MPH- $\alpha$, the percentage differences was found in this way: for $\alpha(-\omega ; \omega)$ an increase of $13.75 \%$ (14.19\%); for $\beta \| z(-2 \omega ; \omega, \omega)$ the increase was $90.62 \%$ $(103.62 \%)$ and for $\gamma(-2 \omega ; \omega, \omega, 0)$ an increase of $100.97 \%$ (124.54\%).

In the comparison of the conformer MPH- $\beta$ for the gas-phase and chloroform for frequency $\omega=0.0239$ a.u. (0.0428 a.u.) it was found that the linear polarization $\alpha(-\omega ; \omega)$ had an increase of $13.75 \%(14.12 \%)$; for the first hyperpolarizability $\beta \| z(-2 \omega ; \omega, \omega)$ the increase of $77.41 \%(90.13 \%)$, and for the second hyperpolarizability $\gamma(-2 \omega ; \omega, \omega, 0)$ an increase of $84.02 \%(63.04 \%)$. When comparing the gas-phase with the DMSO solvent it was found for $\alpha(-\omega ; \omega)$ an increase of $13.75 \%$ (14.19\%); for $\beta \| z(-2 \omega ; \omega, \omega)$ the increase of $90.34 \%(103.26 \%)$, and for $\gamma(-2 \omega ; \omega, \omega, 0)$ an increase of $101.05 \%(81.42 \%)$.

To compare the percentage difference between the mentioned properties of these two conformers, we look at the Tables 7 and 8: the properties displayed by them are practically the same, with a significant difference only for the linear polarizability when the solvent is water; in this case it was found an increase of $48 \%$ between one conformer and the other. The values of $\alpha(-\omega ; \omega)$, $\beta \| z(-2 \omega ; \omega, \omega)$, and $\gamma(-2 \omega ; \omega, \omega, 0)$ are much more sensitive to the presence of solvents.

\section{Frontier molecular orbitals}

The energies of the highest occupied molecular orbital (HOMO) and lowest unoccupied molecular orbital (LUMO) are important in chemical reactions involving radicals ${ }^{41}$ and the energy difference between HOMO-LUMO (band-gap) is an important index of chemical stability; ${ }^{42}$ all these characteristics are important and can be observed experimentally. The band-gap power is one of the parameters used to control NLO properties. There are two alternatives to control the band-gap: through structural modifications and via the inclusion of solvents; so the HOMO-LUMO energy can increase or decrease. When verifying the values of the band-gap of MPH- $\alpha$ and MPH- $\beta$ in the gas phase, it was noted that they are identical (see Figures $8 \mathrm{a}$ and $8 \mathrm{~b}$ ), the same occurring in solvent medium DMSO (see Figures $8 \mathrm{c}$ and $8 \mathrm{~d}$ ). Now, when it was compared the band-gap of the gas-phase with the DSMO for both conformers, it was observed a reduction of de $2.77 \%$ in its band-gap. Since the first hyperpolarizability can be connected to the HOMO-LUMO band-gap energy, then the lower the energy band-gap increase the first hyperpolarizability; this indicates that the molecule in DMSO medium for both the conformers has potential applications in NLO. ${ }^{43}$

\section{Conclusions}

The analysis of the surfaces of Hirshfeld showed agreement with the results previously found for the pattern 
Table 7. Results for the ratio between MPH- $\alpha$ and MPH- $\beta$ for various solvent and at frequency $\omega=0.0239$ a.u. (1906.4 nm)

\begin{tabular}{lccccc}
\hline \multirow{2}{*}{ Medium } & $\alpha(-\omega ; \omega)^{\mathrm{MPH}-\alpha}$ & $\frac{\beta \| \mathrm{z}(-\omega ; \omega, 0)^{\mathrm{MPH}-\alpha}}{\beta \| \mathrm{MP}-\beta}$ & $\frac{\beta \| \mathrm{z}(-2 \omega ; \omega, \omega)^{\mathrm{MPH}-\alpha}}{\beta \| z(-2 \omega ; \omega, \omega)^{\mathrm{MPH}-\beta}}$ & $\frac{\gamma(\omega ; \omega, 0,0)^{\mathrm{MPH}-\alpha}}{\gamma(\omega ; \omega, 0,0)^{\mathrm{MPH}-\beta}}$ & $\frac{\gamma(-2 \omega ; \omega, \omega, 0)^{\mathrm{MPH}-\alpha}}{\gamma(-2 \omega ; \omega, \omega, 0)^{\mathrm{MPH}-\beta}}$ \\
\hline Gas-phase & $\alpha(-\omega ; \omega)^{\mathrm{MPH}-\beta}$ & 1.94 & 1.98 & 0.00 & 0.00 \\
Methanol & 0.00 & 2.02 & 2.05 & -0.01 & -0.02 \\
Water & 0.00 & 2.03 & 2.08 & -0.03 & -0.01 \\
Acetone & 48.19 & 2.07 & 2.04 & -0.03 & -0.02 \\
Ethanol & 0.00 & 2.06 & 2.07 & -0.01 & -0.01 \\
DMSO & 0.00 & 2.07 & 2.12 & -0.05 & -0.04 \\
Chloroform & 0.00 & 2.07 & 2.09 & 0.01 & 0.01 \\
\hline
\end{tabular}

Table 8. Results for the ratio between MPH- $\alpha$ and MPH- $\beta$ for various solvents and at the frequency $\omega=0.0428$ a.u. $(1064.1 \mathrm{~nm})$

\begin{tabular}{lccccc}
\hline \multirow{2}{*}{ Medium } & $\alpha(-\omega ; \omega)^{\mathrm{MPH}-\alpha}$ & $\frac{\beta \| z(-\omega ; \omega, 0)^{\mathrm{MPH}-\alpha}}{\alpha \| z(-\omega ; \omega, 0)^{\mathrm{MPH}-\beta}}$ & $\frac{\beta \| \mathrm{z}(-2 \omega ; \omega, \omega)^{\mathrm{MPH}-\alpha}}{\beta \| \mathrm{z}(-2 \omega ; \omega, \omega)^{\mathrm{MPH}-\beta}}$ & $\frac{\gamma(\omega ; \omega, 0,0)^{\mathrm{MPH}-\alpha}}{\gamma(\omega ; \omega, 0,0)^{\mathrm{MPH}-\beta}}$ & $\frac{\gamma(-2 \omega ; \omega, \omega, 0)^{\mathrm{MPH}-\alpha}}{\gamma(-2 \omega ; \omega, \omega, 0)^{\mathrm{MPH}-\beta}}$ \\
\hline Gas-phase & $\alpha(-\omega ; \omega)^{\mathrm{MPH}-\beta}$ & 1.95 & 1.97 & 0.00 & -23.81 \\
Methanol & 0.00 & 2.03 & 2.09 & -0.02 & -0.03 \\
Water & 0.00 & 2.07 & 2.12 & -0.01 & -0.01 \\
Acetone & 48.18 & 2.07 & 2.09 & -0.03 & -0.03 \\
Ethanol & 0.00 & 2.06 & 2.08 & -0.01 & -0.01 \\
DMSO & 0.00 & 2.09 & 2.14 & -0.04 & -0.03 \\
Chloroform & 0.00 & 2.09 & 2.09 & 0.00 & 0.00 \\
\hline
\end{tabular}
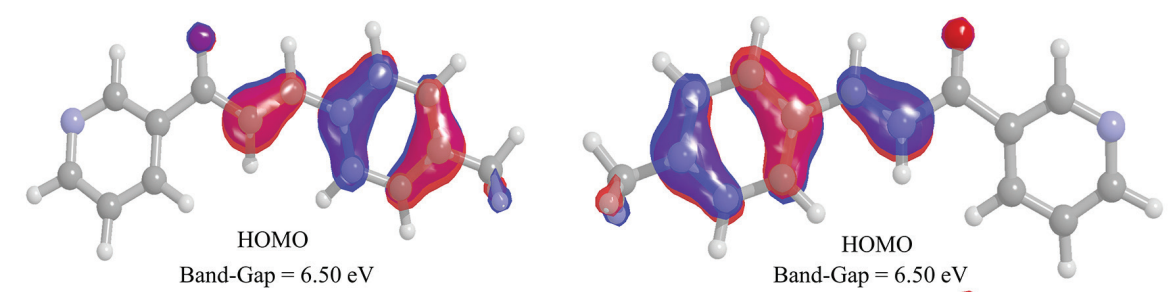

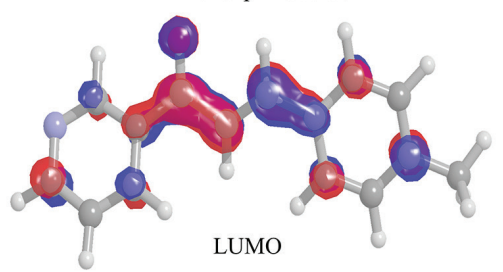

(a)
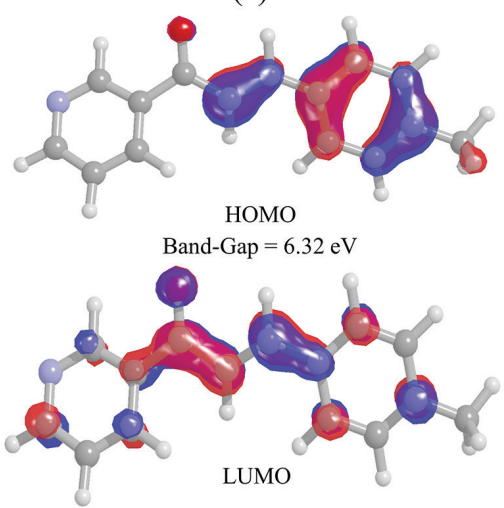

(c)

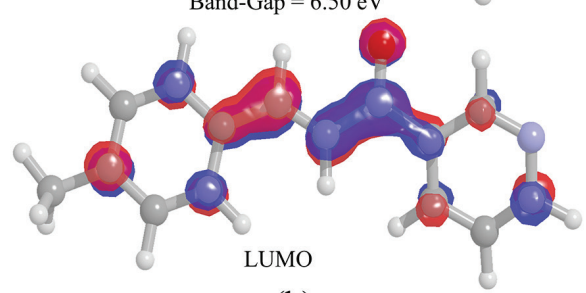

(b)

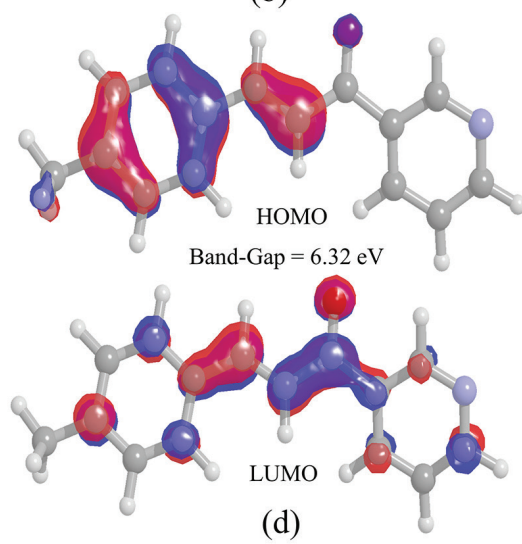

Figure 8. HOMO-LUMO of the molecules MPH- $\alpha$ in gas-phase (a), MPH- $\beta$ in gas-phase (b), MPH- $\alpha$ in DMSO medium (c) and MPH- $\beta$ in DMSO medium (d). 
of intermolecular interactions and crystal packing of the title compound. The intensity of the interactions on the normalized surfaces showed a greater stabilizing effect for the interactions involving the toluyl and carbonyl groups when compared to the dimeric interactions present in the pyridine. In addition, the $\pi \cdots \pi$ and $\mathrm{C}-\mathrm{H} \cdots \pi$ interactions were confirmed by means of the analysis of the surfaces of indexed form, completing the crystalline arrangement of MPH. The conformers MPH- $\alpha$ and MPH- $\beta$ exhibit a decrease in the band-gap energy; when compared their performance in gas-phase with those in DMSO the results indicate that these conformers exhibit interesting nonlinear effects in their electric and optical properties for potential applications in NLO devices, as those exhibited by their first hyperpolarizability.

\section{Supplementary Information}

Crystallographic data (excluding structure factors) for the structures in this work were deposited in the Cambridge Crystallographic Data Centre as supplementary publication number CCDC 896488 . Copies of the data can be obtained, free of charge, via www.ccdc.cam.ac.uk/conts/retrieving. $\mathrm{html}$ or from the Cambridge Crystallographic Data Centre, CCDC, 12 Union Road, Cambridge CB2 1EZ, UK; fax: +44 1223 336033. E-mail: deposit@ccdc.cam.ac.uk.

\section{Acknowledgments}

The authors are grateful to Conselho Nacional de Desenvolvimento Científico e Tecnológico for the financial support to carry out this work.

\section{References}

1. Avupati, V. R.; Rajendra, P.; Yejella, P.; WJPPS 2014, 3, 1713.

2. Suwito, H.; Kristanti, A. N.; Nyoman, N.; Puspaningsih, T.; J. Chem. Pharm. Res. 2014, 6, 1076.

3. Ternavisk, R. R.; Camargo, A. J.; Machado, F. B. C.; Rocco, J. A. F. F.; Aquino, G. L. B.; Silva, V. H. C.; Napolitano, H. B.; J. Mol. Model. 2014, 20, 2526.

4. Custodio, J. M. F.; Vaz, W. F.; de Andrade, F. M.; Camargo, A. J.; Oliveira, G. R.; Napolitano, H. B.; J. Mol. Struct. 2017, 1136, 69 .

5. Tran, T. D.; Nguyen, T. T. N.; Do, T. H.; Huynh, T. N. P.; Tran, C. D.; Thai, K. M.; Molecules 2012, 17, 6684.

6. Yerragunta, V.; Kumaraswamy, T.; Suman, D.; Anusha, V.; Patil, P.; Samhitha, T.; PharmaTutor 2013, 1, 54.

7. Wang, H.-M.; Zhang, L.; Liu, J.; Yang, Z.-L.; Zhao, H.-Y.; Yang, Y.; Shen, D.; Lu, K.; Fan, Z.-C.; Yao, Q.-W.; Zhang, Y.-M.; Teng, Y.-O.; Peng, Y.; Eur. J. Med. Chem. 2015, 92C, 439.
8. Mahapatra, D. K.; Bharti, S. K.; Asati, V.; Eur. J. Med. Chem. 2015, 98, 69.

9. Bashir, R.; Ovais, S.; Yaseen, S.; Hamid, H.; Alam, M. S.; Samim, M.; Singh, S.; Javed, K.; Bioorg. Med. Chem. Lett. 2011, $21,4301$.

10. Chen, M.; Christensen, S. B.; Zhai, L.; Rasmussen, M. H.; Theander, T. G.; FrØkjaer, S.; Steffansen, B.; Davidsen, J.; Kharazmi, A.; J. Infect. Dis. 1997, 176, 1327.

11. Kandaswamy, N.; Raveendiran, N.; Indo Am. J. Pharm. Res. 2014, 4, 3011.

12. Mathew, B.; Suresh, J.; Anbazghagan, S.; Paulraj, J.; Krishnan, G. K.; Biomed. Prev. Nutr. 2014, 4, 451.

13. Wang, G.; Xue, Y.; An, L.; Zheng, Y.; Dou, Y.; Zhang, L.; Liu, Y.; Food Chem. 2015, 171, 89.

14. Albuquerque, H.; Santos, C.; Cavaleiro, J.; Silva, A.; Curr. Org. Chem. 2014, 18, 2750.

15. Detsi, A.; Majdalani, M.; Kontogiorgis, C. A.; HadjipavlouLitina, D.; Kefalas, P.; Bioorg. Med. Chem. 2009, 17, 8073.

16. Sharma, S.; Kaur, C.; Budhiraja, A.; Nepali, K.; Gupta, M. K.; Saxena, A. K.; Bedi, P. M. S.; Eur. J. Med. Chem. 2014, 85, 648.

17. Battle, G. M.; Ferrence, G. M.; Allen, F. H.; J. Appl. Crystallogr. 2010, 43, 1208.

18. Zorkii, P. M.; Razumaeva, A. E.; J. Struct. Chem. 1979, 20, 390.

19. Razumaeva, A. E.; Zorkii, P. M.; J. Struct. Chem. 1980, 21, 184.

20. Taylor, R.; Cole, J. C.; Groom, C. R.; Cryst. Growth Des. 2016 , 16, 2988.

21. Champagne, B.; Bishop, D.; Calculations of Nonlinear Optical Properties for the Solid State; vol. 126; Ottawa, Canada, 2003.

22. Menezes, A. P.; Jayarama, A.; Ng, S. W.; J. Mol. Struct. 2015 , $1088,85$.

23. Chemla, D. S.; Nonlinear Optical Properties of Organic Molecules and Crystals; Elsevier: Amsterdam, Netherlands, 1987.

24. Vaz, W. F.; Custodio, J. M. F.; Silveira, R. G.; Castro, A. N.; Campos, C. E. M.; Anjos, M. M.; Oliveira, G. R.; Valverde, C.; Baseia, B.; Napolitano, H. B.; RSC Adv. 2016, 6, 79215.

25. Oliveiria, M. S.; de Souza, W. C.; Napolitano, H. B.; Oliver, A. G.; Acta Crystallogr., Sect. E: Struct. Rep. Online 2012, 68, o2585.

26. Sheldrick, G. M.; Acta Crystallogr. Sect. A 2008, 64, 112.

27. Sheldrick, G. M. ; Acta Crystallogr. Sect. C Struct. Chem. 2015 , 71,3 .

28. Macrae, C. F.; Edgington, P. R.; McCabe, P.; Pidcock, E.; Shields, G. P.; Taylor, R.; Towler, M.; van de Streek, J.; J. Appl. Crystallogr. 2006, 39, 453.

29. Pedretti, A.; Villa, L.; Vistoli, G.; J. Comput.-Aided Mol. Des. 2004, 18, 167.

30. McKinnon, J. J.; Turner, M. J.; Jayatilaka, D.; Spackman, M. A.; Grimwood, D. J.; Wolff, S. K.; Crystal Explorer (Version 3.1); Australia, 2012. 
31. McKinnon, J. J.; Spackman, M. A.; Mitchell, A. S.; Acta Crystallogr., Sect. B 2004, 60, 627.

32. Spackman, M. A.; Jayatilaka, D.; CrystEngComm 2009, 11, 19.

33. Soudani, S.; Ferretti, V.; Jelsch, C.; Lefebvre, F.; Ben Nasr, C.; Inorg. Chem. Commun. 2015, 61, 187.

34. Spackman, M. A.; McKinnon, J. J.; CrystEngComm 2002, 4, 378.

35. Frisch, M. J.; Trucks, G. W.; Schlegel, H. B.; Scuseria, G. E.; Robb, M. A.; Cheeseman, J. R.; Scalmani, G.; Barone, V.; Mennucci, B.; Petersson, G. A.; Nakatsuji, H.; Caricato, M.; Li, X.; Hratchian, H. P.; Izmaylov, A. F.; Bloino, J.; Zheng, G.; Sonnenberg, J. L.; Hada, M.; Ehara, M.; Toyota, K.; Fukuda, R.; Hasegawa, J.; Ishida, M.; Nakajima, T.; Honda, Y.; Kitao, O.; Nakai, H.; Vreven, T.; Montgomery Jr., J. A.; Peralta, J. E.; Ogliaro, F.; Bearpark, M.; Heyd, J. J.; Brothers, E.; Kudin, K. N.; Staroverov, V. N.; Kobayashi, R.; Normand, J.; Raghavachari, K.; Rendell, A.; Burant, J. C.; Iyengar, S. S.; Tomasi, J.; Cossi, M.; Rega, N.; Millam, J. M.; Klene, M.; Knox, J. E.; Cross, J. B.; Bakken, V.; Adamo, C.; Jaramillo, J.; Gomperts, R.; Stratmann, R. E.; Yazyev, O.; Austin, A.
J.; Cammi, R.; Pomelli, C.; Ochterski, J. W.; Martin, R. L.; Morokuma, K.; Zakrzewski, V. G.; Voth, G. A.; Salvador, P.; Dannenberg, J. J.; Dapprich, S.; Daniels, A. D.; Farkas, Ö.; Foresman, J. B.; Ortiz, J. V; Cioslowski, J.; Fox, D. J.; Gaussian 09, Revision A.02; Gaussian Inc: Wallingford, CT, 2009.

36. Farrugia, L. J.; J. Appl. Crystallogr. 2012, 45, 849.

37. Spek, A. L.; J. Appl. Crystallogr. 2003, 36, 7.

38. Desiraju, G. R.; Acc. Chem. Res. 1996, 29, 441.

39. Chakravorty, S.; Platts, J. A.; Das, B. K.; Dalton Trans. 2011, 40, 11605.

40. Platts, J. A.; Howard, S. T.; Woźniak, K.; Chem. Commun. 1996, 63.

41. Pearson, R. G.; Proc. Natl. Acad. Sci. U. S. A. 1986, 83, 8440.

42. Sklenar, H.; Jäger, J.; Int. J. Quantum Chem. 1979, 16, 467.

43. Arshad, M.; Bibi, A.; Mahmood, T.; Asiri, A.; Ayub, K.; Molecules 2015, 20, 5851.

Submitted: April 3, 2017

Published online: July 13, 2017 